\title{
ANALISIS KINERJA JALAN PADA RUAS JALAN LINTAS MEULABOH - TAPAK TUAN KABUPATEN NAGAN RAYA
}

\author{
Hilma Erliana* \\ Cut Liliiza Yusra \\ Farzi Rizka \\ Akademi Komunitas Negeri Aceh Barat
}

\begin{abstract}
The Meulaboh - Tapak Tuan road is the main access road linking several districts, Aceh Barat, Aceh Barat Daya, Aceh Selatan, and Aceh Tengah. After the earthquake and tsunami hit Aceh, its economies experienced rapid growth. This greatly influences the distribution of traffic volume on specific road segments, including the increasingly congested Meulaboh - Tapak Tuan roads. As a result, the number of private vehicles is increasing. The purpose of this research is to evaluate the performance of roads in the area based on the Indonesian Road Capacity Manual, as well as to analyze the level of road services at present and in the future. The analysis of the road performance can be measure by several indicators such as traffic flow (Q), capacity (C), degree of saturation (DS), free flow velocity (FV), and level of service on the road section. The calculations were obtained from 3 days direct observation in the field from 07:00 to 19:00 with Monday and Thursday representing workdays and Saturday representing weekend. The highest conversion value of traffic flow in 2020 was 1357 pcu/hour for (Q), 2654 $\mathrm{pcu} /$ hour for the actual capacity value (C), and 0.51 for the degree of saturation (DS). The analysis results show that the degree of saturation < 0.75. According to Marga (1997), it is considered in good condition with smooth traffic flow at the service level of $\mathrm{C}$. The road performance analysis for the next five years for traffic flow was 2093 pcu/hour for Q and 0.79 for the degree of saturation (DS). The service level is categorized as level D. It is necessary to find solutions and alternatives to reduce the degree of saturation (DS) value by increasing the value of capacity.
\end{abstract}

Keywords:

Road Performance, Traffic Volume, Service Level

\begin{abstract}
Abstrak
Ruas jalan lintas Meulaboh - Tapak Tuan merupakan akses yang menghubungkan beberapa kabupaten yaitu Aceh Barat, Aceh Barat Daya, Aceh Selatan, Aceh tengah dan lainnya. Pasca gempa dan tsunami menerjang, pertumbuhan ekonomi pada Provinsi Aceh mengalami kemajuan yang cukup pesat. Hal ini sangat mempengaruhi penyebaran volume lalu lintas pada ruas-ruas jalan tertentu termasuk ruas jalan lintas Meulaboh - Tapak Tuan semakin padat. Adapun tujuan penelitian ini adalah melakukan evaluasi kinerja terhadap ruas jalan pada kawasan tersebut berdasarkan Manual Kapasitas Jalan Indonesia, dan menganalisis tingkat pelayanan jalan pada saat ini maupun di masa yang akan datang. Dalam menganalisis kinerja ruas jalan indikator kinerja yang dibutuhkan yaitu arus lalu lintas (Q), kapasitas (C), derajat Kejenuhan (DS), Kecepatan arus bebas (FV) dan tingkat pelayanan pada raus jalan tersebut. Hasil perhitungan yang di dapat selama 3 hari pengamatan langsung di lapangan dari pukul 07.00-19.00 wib yaitu hari senin dan kamis mewakili hari kerja, hari sabtu mewakili hari libur. Didapat nilai konversi tertinggi arus lalu lintas pada Tahun 2020 (Q) sebesar 1357 smp/jam, nilai kapasitas aktual (C) sebesar $2654 \mathrm{smp} / \mathrm{jam}$, derajat kejenuhan (DS) sebesar 0,51. Dari hasil perhitungan didapat derajat kejenuhan <0,75 (Marga, 1997) dianggap dalam kondisi baik, arus stabil, kecepatan dipengaruhi oleh lalu lintas dengan tingkat pelayanan C. Perhitungan analisis kinerja jalan pada 5 tahun mendatang yaitu untuk arus lalu lintas Tahun 2025 (Q) sebesar $2093 \mathrm{smp} / \mathrm{jam}$ derajat kejenuhan (DS) sebesar 0,79 tingkat pelayanannya dikategorikan tingkat D. Hal tersebut dapat dicari solusi terbaik sehingga dapat menurunkan nilai derajat kejenuhan (DS) dengan cara meningkatkan nilai kapasitas.
\end{abstract}

Kata Kunci:

Kinerja Ruas Jalan, Volume Lalu Lintas, Tingkat pelayanan

DOI: $10.38038 /$ vocatech.v2i1.39

Received: 01 Agustus 2020 ; Accepted: 17 September 2020 ; Published: 15 October 2020

"Corresponding author:

Hilma Erliana, Konstruksi Pondasi, Beton dan Pengaspalan Jalan, Akademi Komunitas Negeri Aceh Barat, Jln. Iskandar Muda - Komplek STTU Alue Peunyareng, Meulaboh - Aceh Barat.

Email: hilmaerliana@aknacehbarat.ac.id

Citation in APA Style: Erliana, H., Yusra, C.L., Rizka,F. (2020). Analisis Kinerja Jalan Pada Ruas Jalan Lintas Meulaboh - Tapak Tuan Kabupaten Nagan Raya. VOCATECH: Vocational Education and Technology Journal 2. (1), 1-10. 


\section{PENDAhuluan}

Mobilitas keseharian masyarakat Indonesia paling banyak menggunakan jalan sebagai prasarana tranportasi. Kapasitas dan kemampuan dukung dipengaruhi oleh volume kendaraan yang melewati ruas jalan tersebut (Budiarto, 2015).

Ruas jalan Meulaboh - Tapak Tuan merupakan jalan dengan tipe jalan 2 lajur tak terbagi yang merupakan akses utama dan penghubung beberapa kabupaten yaitu kabupaten Aceh Barat, Aceh Barat Daya, Aceh Selatan, Aceh Tengah dan yang lainnya. Kawasan sepanjang ruas jalan ini merupakan kawasan permukiman penduduk, pertokoan, dan perkantoran. Kendaraan yang melewati ruas jalan tersebut sangat bervariasi mulai dari sepeda motor, kendaraan ringan, bus kecil, truk besar dan lain sebagainya. Hal ini dikarenakan memang ruas jalan tersebut adalah jalan luar kota yang merupakan akses utama beberapa kabupaten (Budiarto, 2015).

Pasca gempa dan tsunami menerjang, pertumbuhan ekonomi pada provinsi Aceh mengalami kemajuan yang cukup pesat sehingga meningkatnya kesejahteraan masyarakat. Akibatnya angka kepemilikan kendaraan bermotor semakin meningkat. Hal ini sangat mempengaruhi penyebaran volume lalu lintas pada ruas-ruas jalan tertentu termasuk ruas jalan Meulaboh - Tapak Tuan yang semakin padat sehingga kinerja ruas jalan tersebut semakin menurun. Penurunan kinerja disebabkan oleh penurunan kecepatan kendaraan sebagai akibat dari kemacetan. Faktor penurunan kinerja diantaranya pertumbuhan lalu lintas yang tidak diimbangi dengan penambahan kapasitas jalan, banyaknya jumlah akses yang dapat menjadi titik konflik lalu lintas, serta perkembangan tata guna lahan yang dapat memicu kebutuhan bergerak (Samponu et al., 2015).

Kapasitas ruas jalan harus ditentukan terlebih dahulu agar analisa kinerja ruas jalan dapat dilakukan. Penentuan kapasistas ruas jalan dihitung dengan cara MKJI 1997 dan metode lainnya. Metode lainnya yang dimaksud adalah dengan menganalisa perilaku karakteristik arus lalu lintas seperti volume (flow), kecepatan (speed) dan kepadatan (density). Jika volume dan kecepatan diketahui, maka kapasitas dari ruas jalan pun dapat diketahui (Mudiyono \& Anindyawati, 2017).

Beberapa penelitian pernah dilakukan mengenai analisis kinerja jalan antara lain; (Mudiyono \& Anindyawati, 2017) melakukan penelitian mengenai analisis kinerja ruas jalan majapahit kota semarang dengan hasil penelitian arus lalu lintas $(\mathrm{Q})=4924,2 \mathrm{smp} / \mathrm{jam}$, nilai kapasitas $(\mathrm{C})=5559,84$, derajat kejenuhan $(\mathrm{DS})=$ 0,88 , kecepatan arus bebas $(\mathrm{FV})=47,79 \mathrm{~km} / \mathrm{jam}$ serta tingkat pelayanan jalan dikategorikan tingkat E. Peningkatan nilai kapasitas diperlukan agar nilai derajat kejenuhan (DS) dapat diturunkan.

Budiarto (2015) juga melakukan penelitian terkait analisis kinerja jalan luar kota samarinda Balikpapan pada ruas jalan soekarno-hatta dimana arus kendaraan $(\mathrm{Q})$ segmen $1=731 \mathrm{kend} / \mathrm{jam}$, segmen $2=726 \mathrm{kend} / \mathrm{jam}$, kapasitas (C) segmen 1 dan $2=2593,5 \mathrm{smp} / \mathrm{jam}$, derjat kejenuhan (DS) segmen $1=0,281$ dan segmen $2=0,279$ dimana tingkat pelayanan kedua segmen adalah A.

Selanjutnya Alisa (2017) juga melakukan evaluasi kapasitas ruas jalan pantai utara Kabupaten Brebes yang dibagi dalam 16 ruas dan 15 simpang pada lima kecamatan dengan volume arus lalu lintas terbesar pada jam puncak pagi yaitu $5034 \mathrm{smp} / \mathrm{jam}$ dan jam puncak sore yaitu $4886 \mathrm{smp} / \mathrm{jam}$, kapasitas kendaraan jam puncak pagi yaitu 2803,20 smp/jam dan jam puncaak sore 2834,20 smp/jam sedangkan tingkat pelayanan rata-rata pada setiap ruas jalan LoS C, D dan E

Adapun maksud dari penelitian yang ingin dilakukan adalah mengukur dan mengevaluasi kinerja pada ruas jalan lintas Meulaboh - Tapak Tuan, memprediksi kinerja jalan atau tingkat pelayanan jalan pada saat ini dan pelayanan jalan untuk lima tahun ke depan serta memberikan alternatif penanganan berdasarkan dari indikator tingkat pelayanan ruas jalan tersebut.

\section{STUDI PUSTAKA}

\section{A. Definisi Jalan Luar Kota}

Menurut Marga (1997) bagian dari jalan luar kota merupakan kondisi dimana tidak adanya perkembangan yang terus menerus pada sisi manapun, namun ada juga sebagian perkembangan yang terjadi bahhkan sering terjadi, contohnya seperti rumah makan, pabrik atau perkampungan. Tipe jalan luar kota terbagi sebagai berikut :

a. Jalan dua-lajur dua-arah tak terbagi (2/2UD)

b. Jalan empat-lajur dua-arah tak terbagi tanpa median (4/2UD) dan terbagi dengan median $(4 / 2 \mathrm{D})$

c. Jalan enam-lajur dua arah terbagi (6/2D) 


\section{B. Indikator Kinerja Jalan}

Adapun perhitungan untuk indikator kinerja jalan luar kota adalah mencakup Marga (1997) :

1. Arus dan komposisi lalu lintas

Nilai arus lalu lintas (Q) merupakan komposisi dari lalu-lintas, yaitu disebut dengan arus dalam satuan mobil penumpang (smp). Adapun nilai dari arus lalu-lintas (per arah dan total) dikonversikan menjadi satuan mobil penumpang (smp) dengan menggunaan ekivalensi mobil penumpang (emp) yang diturunkan secara empiris untuk tipe kendaraan berikut :

a. Kendaraan ringan (meliputi mobil penumpang, minibus, truk pick up dan jeep) $=$ LV

b. Kendaraan berat menengah (meliputi truk tiga gandar dan truk gandingan $)=\mathrm{MHV}$

c. Bus besar $=\mathrm{LB}$

d. Truk besar (meliputi truk tiga gandar dan truk gandingan $=\mathrm{LT}$

e. Sepeda motor $=$ MC

\section{Kecepatan arus bebas}

Kecepatan arus bebas dapat diartikan kecepatan pada setiap tikungan arus nol, sesuai dengan kecepatan berdasarkan keinginan pengemudi seandainya mengendarai kendaraan bermotor tanpa adanya hambatan dari kendaraan bermotor lain yang ada di ruas jalan (yaitu saat arus $=0$ )

Persamaan untuk penentuan kecepatan arus bebas mempunyai bentuk umum berikut :

$$
\mathrm{FV}=\left(\mathrm{FV}_{0}+\mathrm{FV}_{\mathrm{w}}\right) \times \mathrm{FFV}_{\mathrm{SF}} \times \mathrm{FFV}_{\mathrm{RC}} \ldots(2.1)
$$

Dimana:

$\mathrm{FV}=$ Kecepatan arus bebas kendaraan ringan pada kondisi lapangan $(\mathrm{km} / \mathrm{jam})$

$\mathrm{FV}_{0}=$ Kecepatan arus bebas dasar kendaraan ringan pada jalan dan alinyemen yang diamati

$\mathrm{FV}_{\mathrm{w}}=$ Penyesuaian kecepatan akibat lebar jalan $(\mathrm{km} / \mathrm{jam})$

$\mathrm{FFV}_{\mathrm{SF}}=$ Faktor penyesuaian akibat hambatan samping dan lebar bahu

$\mathrm{FFV}_{\mathrm{RC}}=$ Faktor penyesuaian akibat kelas fungsi jalan dan guna lahan

\section{Kapasitas}

Kapasitas merupakan arus puncak (maksimum) pada saat mengendarai kendaraan bermotor berdasarkan persatuan jam yang melewati suatu titik pada ruas jalan dalam kondisi saat ini. Adapun Kapasitas dapat dinyatakan dalam satuan mobil penumpang (smp), persamaan dasar untuk penentuan kapasitas adalah sebagai berikut :

$$
\mathrm{C}=\mathrm{C}_{0} \times \mathrm{FC}_{\mathrm{W}} \times \mathrm{FC}_{\mathrm{SP}} \times \mathrm{FC}_{\mathrm{SF}} \ldots
$$

Di mana :

C $=$ Kapasitas $(\mathrm{smp} / \mathrm{jam})$

$\mathrm{C}_{0} \quad=$ Kapasitas dasar (smp/jam)

$\mathrm{FC}_{\mathrm{W}}=$ Faktor penyesuaian lebar jalan

$\mathrm{FC}_{\mathrm{SP}}=$ Faktor penyesuaian pemisahan arah (hanya untuk jalan tak terbagi)

$\mathrm{FC}_{\mathrm{SF}}=$ Faktor penyesuaian hambatan samping dan bahu jalan

\section{Derajat Kejenuhan}

Definisi dari derajat kejenuhan merupakan rasio arus lalu lintas terhadap kapasitas, yang digunakan sebagai kunci utama dalam menentukan sikap dalam berlalu-lintas pada suatu simpang maupun segmen jalan. Nilai dari derajat kejenuhan menjelaskan apakah segmen pada ruas jalan akan memiliki masalah terhadap kapasitas maupun tidak.

$$
\mathrm{DS}=\mathrm{Q} / \mathrm{C} \ldots(2.3)
$$

Nilai derajat kejenuhan diperbolehkan untuk transportasi.

(DS) yang

\section{Kecepatan}

Kecepatan tempuh dapat diartikan dalam manual ini sebagai kecepatan rata-rata ruang dari kendaraan ringan sepanjang segmen jalan :

$$
\mathrm{V}=\mathrm{L} / \mathrm{T} \ldots(2.4)
$$

Dimana :

$\mathrm{V}=$ Kecepatan ruang rata-rata kendaraan ringan $(\mathrm{km} / \mathrm{jam})$

$\mathrm{L} \quad=$ Panjang segmen $(\mathrm{km})$

TT = waktu tempuh rata-rata dari kendaraan ringan sepanjang segmen (jam) 


\section{Tingkat Pelayanan Jalan (Level of Service)}

Adapun berdasarkan US HCM kinerja ruas jalan berasal dari sautu tingkat pelayanan (LOS), merupakan suatu ukuran kualitatif dalam memahami persepsi pengendara mengenai kualitas kendaraan (Mudiyono \& Anindyawati, 2017).

Apabila terjadi peningkatan volume arus lalu lintas pada suatu ruas jalan serta perubahan dari kondisi geometric ruas jalan tersebut akan dapat mempengaruhi nilai dari tingkat pelayanan pada suatu ruas jalan. Tingkat pelayanan pada suatu ruas jalan atau Level of Service (LOS) dapat dijadikan sebagai parameter dalam keterkaitan antara indikator nilai dari kecepatan, kepadatan dan tingkat pelayanan pada suatu arus lalu lintas. Adapun untuk menghitung tingkat pelayanan jalan dapat dinyatakan dalam persamaan sebagai berikut (Wie et al., 2019) :

$$
\operatorname{LOS}=\mathrm{V} / \mathrm{C} \ldots(2.5)
$$

Di mana :

$$
\begin{array}{ll}
\text { LOS } & =\text { level of service } \\
\mathrm{V} & =\text { volume lalu lintas }(\mathrm{smp} / \mathrm{jam}) \\
\mathrm{C} & =\text { kapasitas aktual }(\mathrm{smp} / \mathrm{jam})
\end{array}
$$

Tabel 1. Standar tingkat pelayanan jalan

\begin{tabular}{|c|c|c|}
\hline V/C & $\begin{array}{c}\text { Tingkat } \\
\text { Pelayanan Jalan }\end{array}$ & Keterangan \\
\hline $0.00-0.19$ & $\mathrm{~A}$ & $\begin{array}{c}\text { Arus lancar, volume } \\
\text { rendah, kecepatan tinggi }\end{array}$ \\
\hline $0.20-0.44$ & $\mathrm{~B}$ & $\begin{array}{c}\text { Arus stabil, kecepatan } \\
\text { terbatas, volume sesuai } \\
\text { untuk luar kota }\end{array}$ \\
\hline $0.45-0.74$ & $\mathrm{C}$ & $\begin{array}{c}\text { Arus stabil,kecepatan } \\
\text { dipengaruhi oleh lalu } \\
\text { lintas, volume sesuai } \\
\text { untuk jalan kota }\end{array}$ \\
\hline $0.75-0.84$ & $\mathrm{D}$ & $\begin{array}{c}\text { Mendekati arus tidak } \\
\text { stabil, kecepatan rendah }\end{array}$ \\
\hline $0.85-1.00$ & $\mathrm{E}$ & $\begin{array}{c}\text { Arus tidak stabil, } \\
\text { kecepatan rendah, } \\
\text { volume padat atau } \\
\text { mendekati kapasitas }\end{array}$ \\
\hline$>1.00$ & $\mathrm{~F}$ & $\begin{array}{c}\text { Arus yang terhambat, } \\
\text { kecepatan rendah, } \\
\text { volume di atas kapasitas }\end{array}$ \\
\hline
\end{tabular}

\section{A. Tahapan Penelitian}

Metode yang akan digunakan dalam menyelesaikan penelitian ini dibagi menjadi beberapa tahapan. Secara garis besar meliputi permasalahan, tinjauan pustaka, survei langsung di lapangan untuk mendapatkan inventarisasi data lapangan yang berupa kondisi geometrik jalan dan volume lalu lintas, pengumpulan data, analisis data, analisis penerapan manajemen lalu lintas, hasil dan kesimpulan.

\section{Lokasi Penelitian}

Lokasi penelitian ini dilaksanakan pada ruas jalan lintas Meulaboh - Tapak tuan Desa Suak Puntong Kecamatan Kuala Pesisir Kabupaten Nagan Raya. Ruas jalan tersebut memiliki lebar jalan 6 meter, kondisi pada sekitar kawasan ini merupakan kawasan permukiman penduduk dan kawasan pusat kegiatan seperti PT. PLTU Nagan Raya, PT. Mifa Bersaudara dan PT. Cipta Kridatama.

\section{Data Penelitian}

Adapun data yang dikumpulkan meliputi data primer dan data sekunder.

\section{a. Data Primer}

Data primer adalah data yang diperoleh dengan pengambilan secara langsung di lapangan yang meliputi :

1). Kondisi geometrik jalan dengan mengukur Panjang dan lebar jalan serta survei hambatan samping dengan melihat apa saja kondisi hambatan samping.

2). Data volume arus lalu-lintas, dilakukan dengan cara perhitungan manual (manual counting) pada satu titik pengamatan yang telah ditentukan di daerah pada ruas jalan Meulaboh - Tapak Tuan. Perhitungan dilakukan dalam periode 15 menit dari pukul 07.00 wib sampai pukul 19.00 wib pada hari senin dan kamis mewakili hari kerja dan hari sabtu mewakili hari libur. Kendaraan yang dihitung dibedakan dalam sepeda motor (MC), kendaraan ringan (LV), Kendaraan menengah berat (MHV), bus besar (LB), truk besar (LT).

3). Alat yang dibutuhkan dalam survei lapangan adalah, formulir survei dan alat tulis, counter untuk menghitung volume lalu lintas terklasifikasi secara manual, jam dan stop watch untuk mengetahui waktu tempuh kendaraan, kamera untuk dokumentasi survei lalu lintas kendaraan, walking measure untuk menghitung panjang atau lebar jalan.

4). Selain survei lapangan juga dilakukan survei wawancara kepada masyarakat yang berada disekitar ruas jalan tersebut (Faisal et al., 2020). Adapun pertanyaan secara umum yang ditanyakan adalah kondisi ruas jalan 
tersebut, kendaraan yang sering dilewati serta kondisi kecelakaan yang sering terjadi.

\section{b. Data Sekunder}

Data sekunder adalah data yang diperoleh dari instansi terkait, meliputi peta situasi ruas jalan dan ukuran kota (jumlah penduduk).

\section{B. Analisis Data}

Analisis pengolahan data dilakukan apabila data primer dan data sekunder telah terkumpul, dalam analisis data yang diperoleh di lapangan diolah dengan menggunakan formula yang telah ditetapkan dalam MKJI 1997. Analisis data dalam penelitian ini meliputi variabel yang digunakan adalah :

1. Volume lalu lintas

Pengumpulan data volume lalu lintas dilakukan selama 3 (tiga) hari pengamatan yang mewakili hari sibuk (hari kerja) yaitu hari senin dan kamis dan yang mewakili hari libur yaitu hari sabtu. Waktu pencatatan volume lalu lintas dilakukan dari mulai pukul 08.00 wib sampai dengan 19.00 wib dengan interval waktu pengamatan 15 menit untuk setiap masing-masing arah akan diubah ke dalam satuan mobil penumpang (smp). Pengamatan volume lalu lintas ini bertujuan untuk mendapatkan besarnya volume lalu lintas dalam interval waktu setiap satu jam untuk setiap lajur pada ruas jalan. Dalam menentukan waktu terjadinya jam puncak dari 3 hari pengamatan, maka data volume lalu lintas dengan interval waktu setiap satu jam di plot ke dalam bentuk grafik fluktuasi.

\section{Kecepatan Arus Bebas}

berdasarkan perhitungan dari kecepatan arus bebas yang dapat dihitung berdasarkan dari masing-masing kecepatan rata-rata kendaraan pada tiap lajur di tiap segmen.

\section{Kapasitas Jalan}

Dihitung berdasarkan perkalian antara nilai kapasitas dasar dengan faktor penyesuaian lebar jalan, hambatan samping, pemisah arah dan ukuran kota.

\section{Derajat Kejenuhan (DS)}

Untuk kinerja ruas jalan dan bagian jalinan tunggal, kapasitas aktual (C) harus lebih besar dari arus lalu lintas yang terjadi (Q) dengan diketahui nilai kapasitas jalan (C) dan volume lalu lintas (Q) maka dapat dihitung nilai derajat kejenuhan (DS). Nilai DS $=\mathrm{Q} / \mathrm{C}$ harus lebih kecil dari derajat kejenuhan normal yaitu 0,75 sedangkan untuk jalan tunggal derajat kejenuhan DS harus lebih kecil dari DS rencana yaitu 0,80 .

\section{Tingkat pelayanan}

Menurut (Mudiyono \& Anindyawati, 2017) sikap dari lalu lintas berdasarkan tingkat pelayanan suatu ruas jalan atau Level of Service (LOS) dimana ukuran kualitatif yang mencerminkan persepsi dari pengendara dalam kualitasnya saat mengendarai kendaraan.

\section{Prediksi kinerja jalan 5 tahun ke depan}

Dalam meramalkan kinerja jalan untuk lima tahun ke depan, yang kemungkinan besar berpotensi mempengaruhi mempengaruhi tingkat pelayanan jalan digunakan metode eksponensial, dengan rumus sebagai berikut : (Prasetyo Arifin, 2011).

$$
\mathrm{P}_{\mathrm{n}}=\mathrm{P}_{\mathrm{o}}(1+\mathrm{i})^{\mathrm{n}} \ldots(3.1)
$$

Dimana :

$\mathrm{Pn}=$ Jumlah kendaraan pada tahun ke-n

Po = Jumlah kendaraan pada saat ini/tahun awal

i = Tingkat pertumbuhan kendaraan (\%)

$\mathrm{n} \quad=$ Waktu (tahun).

Berdasarkan data BPS, persentase rata-rata pertumbuhan kepemilikan kendaraan bermotor tahun 2009-2018 tiap tahunnya mencapai 9,05\%. Sehingga untuk menganalisis kinerja jalan untuk lima tahun ke depan yaitu tahun 2025 maka data jumlah kendaraan didapat menggunakan rumus di atas. Untuk memprediksi tingkat pelayanan jalan lima tahun ke depan yaitu tahun 2025 dapat ditentukan dari nilai volume (Q) pada tahun 2025 per kapasitas aktual (C) dan kecepatan kendaraan $\left(\mathrm{V}_{\mathrm{LV}}\right)$.

\section{HASIL DAN PEMBAHASAN}

\section{A. Hasil}

Hasil volume lalu lintas dalam interval 15 menit pada jalan lintas meulaboh - tapak tuan selama tiga hari pengamatan yaitu hari senin, kamis dan sabtu. Senin dan kamis mewakili hari kerja dan sabtu mewakili hari tidak kerja. Dari hasil volume lalu lintas selama tiga hari pengamatan dari pukul $08.00-19.00$ wib dapat 
dilihat pada grafik fluktuasi besarnya volume jamjam puncak pagi, siang dan sore hari.

1. Hasil pengukuran volume lalu lintas pada ruas jalan lintas meulaboh - tapak tuan pada hari senin.

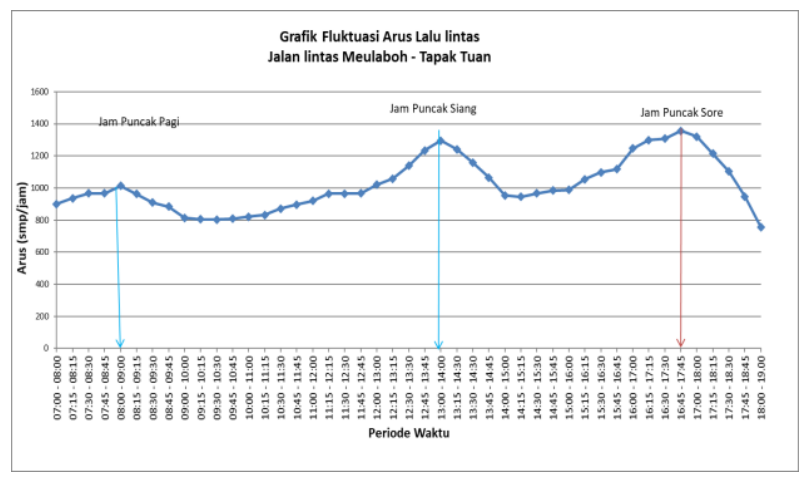

Gambar 1. Fluktuasi Volume Lalu Lintas jalan lintas Meulaboh - Tapak Tuan pada hari senin

Dari grafik dapat dilihat bahwa volume lalu lintas pada jam puncak pagi pada pukul $08.00-09.00$ sebesar 1013 smp/jam, jam puncak siang pada pukul 13.00 - 14.00 sebesar $1295 \mathrm{smp} / \mathrm{jam}$ dan jam puncak sore pada pukul 16.45 - 17.45 sebesar $1357 \mathrm{smp} / \mathrm{jam}$.

2. Hasil pengukuran volume lalu lintas pada ruas jalan lintas meulaboh - tapak tuan pada hari kamis.

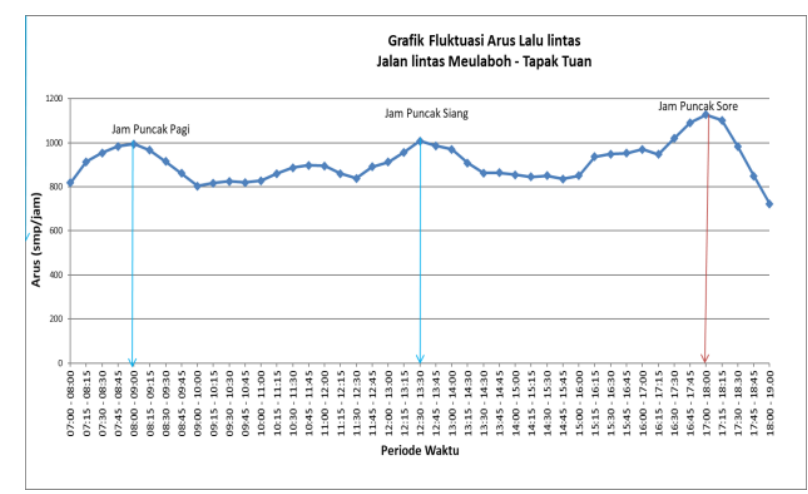

Gambar 2. Fluktuasi Volume Lalu Lintas jalan lintas Meulaboh -Tapak Tuan pada hari kamis

Dari grafik dapat dilihat bahwa volume lalu lintas pada jam puncak pagi pada pukul 08.00 - 09. 00 sebesar $995 \mathrm{smp} / \mathrm{jam}$, jam puncak siang pada pukul 12.30 - 13.30 sebesar 1008 smp/jam dan jam puncak sore pada pukul 17.00 - 18.00 sebesar $1127 \mathrm{smp} / \mathrm{jam}$.

3. Hasil pengukuran volume lalu lintas pada ruas jalan lintas Meulaboh - Tapak Tuan pada hari Sabtu

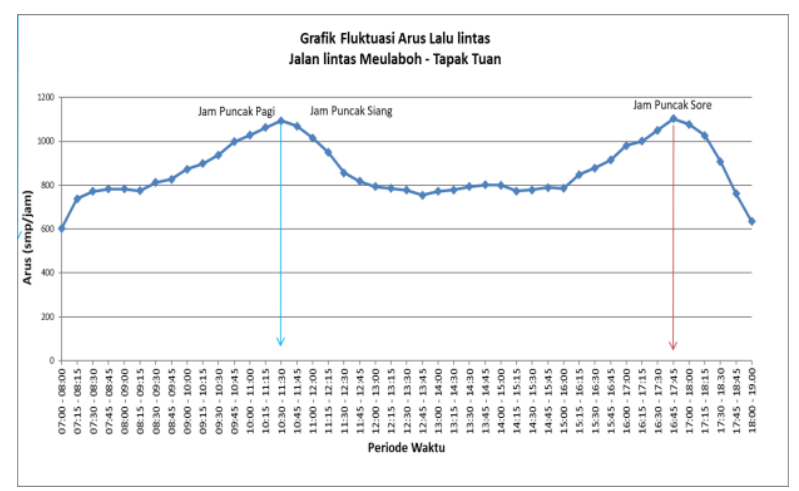

Gambar 3. Fluktuasi Volume Lalu Lintas jalan lintas Meulaboh -Tapak Tuan pada hari sabtu

Dari grafik tersebut dapat dilihat bahwa volume lalu lintas pada jam puncak pagi pada pukul 10.30 - 11.30 sebesar $1094 \mathrm{smp} / \mathrm{jam}$, jam puncak siang pada pukul 10.45 - 11.45 sebesar $1070 \mathrm{smp} / \mathrm{jam}$ dan jam puncak sore pada pukul 16.45 - 17.45 sebesar $1104 \mathrm{smp} / \mathrm{jam}$.

\section{Hasil perhitungan kecepatan arus bebas, kapasitas, kecepatan kendaraan ringan, derajat kejenuhan dan tingkat pelayanan pada ruas jalan lintas Meulaboh - Tapak Tuan}

Untuk mendapatkan perhitungan kecepatan arus bebas, kapasitas, kecepatan kendaraan ringan, derajat kenuhan dan tingkat pelayanan selanjutnya data pencacahan lalu lintas tersebut diolah menggunakan metode MKJI 1997 untu jalan luar kota. Rekapitulasi hasil perhitungan dapat dilihat pada tabel berikut ini :

Tabel 1. Rekapitulasi hasil perhitungan Kinerja Jalan 


\section{Prediksi kinerja jalan untuk 5 tahun ke depan}

Berdasarkan data BPS, persentase rata-rata pertumbuhan kepemilikan kendaraan bermotor tahun 2009-2018 tiap tahunnya mencapai 9,05 \%.(Pertumbuhan Kendaraan Bermotor Sebesar 9,05 Persen _ EWADA, n.d.) Sehingga untuk menganalisis kinerja jalan untuk lima tahun ke depan yaitu tahun 2025 maka data jumlah kendaraan didapat menggunakan rumus di atas. Untuk memprediksi tingkat pelayanan jalan lima tahun ke depan yaitu tahun 2025 dapat ditentukan dari nilai volume (Q) pada tahun 2025 per kapasitas aktual (C) dan kecepatan kendaraan $\left(\mathrm{V}_{\mathrm{LV}}\right)$.

Tabel 2. Prediksi nilai derajat kejenuhan 5 Tahun ke depan.

\begin{tabular}{ccccc}
\hline \multirow{2}{*}{$\begin{array}{c}\text { Umur } \\
\text { Rencana } \\
\text { (Tahun) }\end{array}$} & $\begin{array}{c}\text { Angka } \\
\text { Pertumbuhan } \\
\text { Kendaraan }\end{array}$ & Arus (Q) & $\begin{array}{c}\text { Kahun } \\
\text { Aktualas } \\
\text { Annyyy}\end{array}$ & $\begin{array}{c}\text { Derajat } \\
\text { Kejenuhan }\end{array}$ \\
\hline (n) & $9,05 \%$ & $(\mathrm{C})$ & $(\mathrm{DS})$ \\
\hline 5 & 0,0905 & 2093 & 2654 & 0,79 \\
\hline
\end{tabular}

Dari hasil perhitungan untuk prediksi nilai derajat kejenuhan pada tahun 2025 yaitu DS $=0,79$ dengan tingkat pelayanannya adalah $\mathrm{D}$.

\section{B. Pembahasan}

Berdasarkan hasil perhitungan yang telah dilakukan dapat diketahui volume lalu litas terbanyak dari tiga hari pengamatan yaitu pada hari senin pada jam puncak sore pukul 16.45 17.45 sebesar $1357 \mathrm{smp} / \mathrm{jam}$, dengan nilai derajat kejenuhan (DS) sebesar 0,51 di mana status tingkat pelayanan dengan nilai $\mathrm{C}$ dengan keterangan arus stabil. Sedangkan untuk prediksi kinerja jalan pada 5 tahun ke depan yaitu pada tahun 2025 dengan nilai derajat kejenuhan (DS) sebesar 0,79 di mana status tingkat pelayanan dalam kategori D dengan kondisi arus yang tidak stabill, kecepatan kendaraan rendah, serta volume arus lalu lintas yang padat bahkan mendekati nilai kapasitas.

\section{Solusi Penanganan Permasalahan}

Berdasarkan hasil dan pembahasan di atas berikut ini adalah beberapa alternatif yang dapat dijadikan solusi dalam menangani permasalahan suatu kinerja ruas jalan yaitu sebagai berikut :

Adapun upaya dalam mengatasi tingkat kemacetan dan memperlancar arus lalu lintas yaitu

\begin{tabular}{|c|c|c|c|c|c|}
\hline \multirow[t]{2}{*}{$\begin{array}{l}\text { Periode } \\
\text { Jam } \\
\text { Puncak }\end{array}$} & $\begin{array}{c}\text { Kecepatan } \\
\text { Arus } \\
\text { Bebas } \\
(\mathrm{km} / \mathrm{jam})\end{array}$ & $\begin{array}{l}\text { Kapasitas } \\
\text { (C) }\end{array}$ & \multirow[t]{2}{*}{$\begin{array}{c}\text { Derajat } \\
\text { Kejenuhan }\end{array}$} & \multirow[t]{2}{*}{$\begin{array}{l}\mathrm{Kec} \\
\mathrm{V}_{\mathrm{LV}}\end{array}$} & \multirow[t]{2}{*}{$\begin{array}{l}\text { Tingkat } \\
\text { Pelayanar }\end{array}$} \\
\hline & LV & (smp/jam) & & & \\
\hline & \multicolumn{5}{|c|}{ Senin } \\
\hline $\begin{array}{l}\text { Pagi } \\
08: 00 \text { - } \\
09: 00\end{array}$ & 63,21 & 2654 & 0,38 & 49,8 & A \\
\hline $\begin{array}{l}\text { Siang } \\
13: 00- \\
14: 00\end{array}$ & 63,21 & 2654 & 0,40 & 48,5 & B \\
\hline $\begin{array}{l}\text { Sore } \\
16: 45- \\
17: 45\end{array}$ & 63,21 & 2654 & 0,51 & 46 & $\mathrm{C}$ \\
\hline & \multicolumn{5}{|c|}{ Kamis } \\
\hline $\begin{array}{l}\text { Pagi } \\
08: 00 \text { - } \\
09: 00\end{array}$ & 63,21 & 2654 & 0,32 & 52 & A \\
\hline $\begin{array}{l}\text { Siang } \\
12: 30- \\
13: 30\end{array}$ & 63,21 & 2654 & 0,29 & 52 & A \\
\hline $\begin{array}{l}\text { Sore } \\
17: 00- \\
18: 00 \\
\end{array}$ & 63,21 & 2654 & 0,43 & 48 & B \\
\hline & \multicolumn{5}{|c|}{ Sabtu } \\
\hline $\begin{array}{l}\text { Pagi } \\
10: 30- \\
11: 30\end{array}$ & 63,21 & 2654 & 0,41 & 48,5 & B \\
\hline $\begin{array}{l}\text { Siang } \\
10: 45 \text { - } \\
11: 45\end{array}$ & 63,21 & 2654 & 0,30 & 52,2 & A \\
\hline $\begin{array}{l}\text { Sore } \\
16: 45- \\
17: 45\end{array}$ & 63,21 & 2654 & 0,42 & 48 & B \\
\hline
\end{tabular}

dengan menerapkan manajemen lalu lintas, seperti mengendalikan arus lalu lintas, membuat sistem jalan satu arah baik secara permanen maupun hanya sementara, serta memperlebar ruas jalan (Alhadar, 2011).

Dalam mengatasi tingkat kepadatan suatu ruas jalan tidak bisa hanya dengan dilakukannya pelebaran jalan, namun pemerintah dapat memberikan solusi dengan menerapkan suatu aturan atau kebijakan seperti menghilangkan hambatan samping atau memperkecil arus lalu lintas yang memasuki suatu ruas jalan (Erliana, 2019).

Untuk suatu ruas jalan yang mengalami tingkat kecelakaan tinggi penanganan yang bisa dilakukan yaitu dengan melakukan pengecatan Kembali marka jalan yang sudah mulai memudar namun untuk jangka yang panjang dapat digunakan teknologi cold plastic, pelebaran bahu jalan untuk mengantisipasi kendaraan pada saat berhenti sementara dikarenakan mengalami gangguan teknis, serta perlu dilakukannya penelitian berdasarkan persepsi dari pengguna jalan maupun korban kecelakaan pada rusa jalan tersebut, untuk mendapatkan kondisi keselamatan berlalu-lintas (Fahmi, 2014). 
Menurut Swari et al. (2014) penanganan kemacetan lalu lintas yaitu dengan memasang rambu peringatan atau rawan kecelakaan dengan jarak tertentu, memasang lampu penerangan pasa suatu ruas jalan dan pengecekan berkala kondisi di daerah sekitar, serta memberikan pemahaman kepada masyarakat pentingnya keselamatan berlalu lintas dan juga memberikan sanksi yang tegas bagi pengguna kendaraan yang tidak mematuhi peraturan lalu-lintas.

\section{KESIMPULAN}

\section{A. Kesimpulan}

Kesimpulan dari penelitian ini adalah :

1. hasil perhitungan analisa volume lalu lintas pada ruas jalan lintas Meulaboh - Tapak Tuan selama tiga hari pengamatan, paling tinggi yaitu pada hari senin jam puncak sore pukul 16.45 17.45 sebesar $1357 \mathrm{smp} / \mathrm{jam}$.

2. pada Tahun 2020 (saat ini) nilai derajat kejenuhan DS sebesar 0,51. Sedangkan nilai derajat kejenuhan (DS) 5 tahun ke depan yaitu pada tahun 2025 dengan nilai sebesar 0,79.

3. Kapasitas ruas jalan lintas Meulaboh - Tapak Tuan pada saat ini dikategorikan masih dapat menampung arus lalu lintas yang melewati ruas jalan lintas Meulaboh - Tapak Tuan, namun walaupun masih dapat menampung arus lalu lintas akan tetapi sudah sangat mendekati kapasitas padat, sehingga sering menimbulkan kemacetan. Adapun analisis nilai kapasitas pada ruas jalan ini dapat disimpulkan sebagai berikut : a. Kapasitas Dasar (C) jalan lintas Meulaboh - Tapak Tuan adalah 1357 smp/jam dimana artinya belum memenuhi persyaratan MKJI 1997. Menurut MKJI 1997 (C $\geq 2900)$ b. Derajat Kejenuhan (DS) ruas jalan lintas Meulaboh - Tapak Tuan pada masa mendatang yaitu tahun 2025 adalah 0,79 yang artinya tidak memenuhi persyaratan MKJI 1997, menurut MKJI 1997 nilai $(\mathrm{DS} \leq 0,75)$ c. Tingkat Pelayanan Jalan ruas jalan lintas Meulaboh Tapak Tuan di kategorikan pada nilai D.

\section{B. Saran}

1. Penelitian ini diharapkan bisa menjadi bahan pertimbangan maupun evaluasi bagi pemerintah untuk dapat meningkatkan kinerja ruas jalan tersebut dikemudian hari yaitu dengan memperbaiki sistem manajemen transportasi menjadi lebih baik dan membangun infrastruktur untuk meningkatkan ruang jalan dan dapat menghindari kemacetan di wilayah tersebut.

2. Jalan lintas Meulaboh - Tapak Tuan merupakan jalan utama yang menghubungkan beberapa Kabupaten sehingga apabila arus volume lalu lintas yang semakin meningkat di tiap tahunnya sehingga perlu adanya pelebaran jalan secara keseluruhan agar dapat mencegah kecelakaan lalu lintas serta kemacetan diwilayah ini yang dapat menciptakan suasana yang nyaman dan lancar dalam berlalu-lintas.

\section{REFERENSI}

Alhadar, A. (2011). Analisis kinerja jalan dalam upaya mengatasi kemacetan lalu lintas pada ruas simpang bersinyal di kota palu. SMARTek, 9(4).

Alisa, Y. N. (2017). Evaluasi Kapasitas Ruas Jalan Pantura Kabupaten Brebes. Jurnal Teknik Sipil Dan Perencanaan, 19(1), 71-76.

Budiarto, M. R. (2015). Analisis Kinerja Jalan Luar Kota Samarinda-Balikpapan Pada Ruas Jalan Soekarno-Hatta Pada KM. 17+ 000KM. 37+ 000. Kurva S Jurnal Mahasiswa, 4(1), 1057-1066.

Erliana, H. (2019). Strategi Penanganan Kemacetan Arus Lalu Lintas Berdasarkan Persepsi Masyarakat. VOCATECH: Vocational Education and Technology Journal. https://doi.org/10.38038/vocatech.v1i0.4

Fahmi, K. (2014). Solusi Penanggulangan Kecelakaan Lalu Lintas di Kabupaten Rokan Hulu.

Faisal, R., Mutiawati, C., \& Salmannur, A. (2020). Analisis Kinerja Angkutan Kota dalam Provinsi di Provinsi Aceh Berdasarkan Pendekatan Load Factor. VOCATECH: Vocational Education and Technology Journal, 1(2), 38-44.

Marga, D. B. (1997). Manual Kapasitas Jalan Indonesia (MKJI) 1997. In Departemen PU DirJen Bina Marga.

Mudiyono, R., \& Anindyawati, N. (2017). Analisis Kinerja Ruas Jalan Majapahit Kota Semarang (Studi Kasus: Segmen Jalan Depan Kantor Pegadaian Sampai Jembatan Tol Gayamsari). Prosiding Seminar Nasional Inovasi Dalam Pengembangan SmartCity, l(1). 
Pertumbuhan Kendaraan Bermotor Sebesar 9,05 Persen_EWADA. (n.d.).

Prasetyo Arifin, D. (2011). Analisis Kapasitas Dan Kinerja Pada Simpang Bersinyal (Kasus Simpang Daan Mogot Kota Tangerang). Universitas Komputer Indonesia.

Samponu, I. T. P., Sendow, T. K., \& Manoppo, M. R. E. (2015). Analisa Kinerja Ruas Jalan Manado Bypass Tahap I Di Kota Manado. Jurnal Sipil Statik, 3(6).

Swari, I. G. P. A., Suthanaya, P. A., \& Negara, I. N. W. (2014). Analisis Biaya Dan Penanganan Lokasi Rawan Kecelakaan Akibat Kecelakaan Lalu Lintas Di Kota Denpasar. J. Spektran, 2, 24-30.

Wie, N. R. N., Lefrandt, L. I. R., \& Pandey, S. V. (2019). Kajian Efektifitas Penerapan Zona Selamat Sekolah (Zoss) Di Kota Tomohon (Studi Kasus: SD Negeri 2 Tomohon Dan SD Lentera Harapan Tomohon). Jurnal Sipil Statik, 7(2). 

This works is licensed under a Creative Common Attribution-ShareAlike 4.0 